\title{
CARACTERIZAÇÃO EPIDEMIOLÓGICA DAS INTOXICAÇÕES EXÓGENAS POR SUBSTÂNCIAS NOCIVAS E ACIDENTES POR ANIMAIS PEÇONHENTOS EM CRIANÇAS NO ESTADO DO AMAPÁ
}

\section{ARTIGO ORIGINAL}

NEIVA, Camila Alves Corrêa ${ }^{1}$

AQUINO, Victor Alexandre Nascimento de ${ }^{2}$

CANTANHÊDE, Luíza Alves ${ }^{3}$

ARAÚJO, Maria Helena Mendonça de ${ }^{4}$

FECURY, Amanda Alves ${ }^{5}$

DIAS, Cláudio Alberto Gellis de Mattos ${ }^{6}$

NEIVA, Camila Alves Corrêa. Et al. Caracterização epidemiológica das intoxicações exógenas por substâncias nocivas e acidentes por animais peçonhentos em crianças no Estado do Amapá. Revista Científica Multidisciplinar

${ }^{1}$ Aluna do 6ำ ano do curso de Graduação em Medicina na Universidade Federal do Amapá.

${ }^{2}$ Aluno do 6ำ ano do curso de Graduação em Medicina na Universidade Federal do Amapá.

3 Aluna do 6 ano do curso de Graduação em Medicina na Universidade Federal do Amapá.

${ }^{4}$ Médica, Mestre em Ensino e Ciências da Saúde, Docente da Universidade Federal do Amapá.

${ }^{5}$ Biomédica, Doutora em Doenças Tropicais, Docente da Universidade Federal do Amapá.

${ }^{6}$ Biólogo, Doutor em teoria e pesquisa do comportamento, Docente do Instituto Federal do Amapá. 
Núcleo do Conhecimento. Ano 04, Ed. 09, Vol. 01, pp. 41-66. Setembro de 2019. ISSN: 2448-0959, Link de acesso: https://www.nucleodoconhecimento.com.br/saude/caracterizacaoepidemiologica

\section{RESUMO}

Intoxicações exógenas em crianças são um problema de saúde pública em todo o mundo e são definidas como efeitos nocivos decorrentes do contato com toxinas externas ao organismo. As crianças passam por uma fase de experimentação sensorial que faz com que estejam mais vulneráveis aos agentes tóxicos. No contexto nacional, o Brasil registra de 1,5 a $3 \%$ de novos casos de intoxicação anualmente. $O$ presente estudo objetivou caracterizar epidemiologicamente os casos de intoxicação exógena aguda por substâncias químicas e de acidentes por animais peçonhentos em crianças de zero a 9 anos no Estado do Amapá no período de 2007 a 2017. Foi realizado um estudo epidemiológico, retrospectivo, de análise quantitativa do período de 2007 e 2017 com base no DATASUS, considerando: agente tóxico, ano de ocorrência, sexo, faixa etária, circunstância, gravidade e desfecho clínico. Os dados foram analisados para confecção de gráficos, tabelas e figuras. No período analisado, registrou-se 14 casos de intoxicação exógena por substâncias químicas e 1.000 casos por animais peçonhentos. O número de casos mostrou-se crescente ao longo dos anos. Os meninos são mais acometidos que as meninas em todos os casos de intoxicação. O principal agente causador no geral é a serpente Bothrops. As principais substâncias químicas são os medicamentos. Todos os casos receberam alta após cura. Os acidentes aconteceram em sua maioria no primeiro semestre do ano. A faixa etária mais acometida por animais peçonhentos foi de 5 a 9 anos, já a faixa de 1 a 4 anos foi mais acometida por intoxicações por substâncias químicas.

Palavras-chave: Intoxicação, toxicologia, animais venenosos, epidemiologia. 


\section{INTRODUÇÃO}

Os acidentes por intoxicação exógena são causa frequente de procura por atendimento nos Prontos Socorros durante os primeiros anos de vida da criança. As intoxicações exógenas são conhecidas como um conjunto de sinais e sintomas provocados pela interação de um agente tóxico (ex.: substância química, peçonha) com o organismo, gerando um desequilíbrio orgânico ou estado patológico. Considera-se esse agravo um importante problema de saúde pública, uma vez que têm levado um número crescente de crianças à morte (DOMINGOS, 2016; TAVARES, 2013; VILAÇA, 2014).

Os agentes causadores de intoxicações são variados, e podem ser classificados em: medicamentos, agrotóxicos agrícolas, agrotóxicos domésticos, agrotóxicos de saúde pública, raticidas, produtos veterinários, produto de uso domiciliar, cosméticos, produtos químicos em geral, metais, drogas de abuso, plantas tóxicas, alimentos e bebidas e animais peçonhentos (AMORIM, 2017; TAVARES, 2013).

Diversos fatores estão envolvidos nas intoxicações acidentais que ocorrem na infância, tais como idade, sexo, condições econômicas, sociais, culturais, educacionais e habitacionais. Segundo estudos brasileiros e internacionais, o ambiente domiciliar tem sido apontado como o local de maior risco de contato com agentes tóxicos. Já o ambiente externo à residência costuma ser o local de maior frequência dos acidentes por animais peçonhentos. As crianças mais expostas têm em média 5 anos, idade em que elas possuem mais autonomia e se expõem mais aos riscos ambientais (BRITO, 2015; DOMINGOS, 2016; TAVARES, 2013; VILAÇA, 2014).

No Brasil, os casos de intoxicação exógena fazem parte dos agravos de notificação compulsória, sendo que qualquer unidade de atendimento poderá notificar e repassar os dados ao setor responsável da Secretaria Municipal de Saúde. Hoje, os Centros de Assistência Toxicológica (CEATOX) são as principais unidades notificadoras (DOMINGOS, 2016; VILAÇA, 2014). 
Estão registrados no DATASUS, no ano de 2017, 49.558 casos brasileiros de intoxicação exógena na faixa etária de zero a 9 anos. Destes, mais de 22 mil casos correspondem aos acidentes com substâncias tóxicas, dos quais 34 evoluíram para óbito. Já os acidentes com animais peçonhentos representam mais da metade dos casos (26.749 registros), sendo que 700 foram considerados graves e 55 dessas crianças foram a óbito. Houve aumento de mais de 30.000 casos nos últimos 10 anos, sendo os acidentes por substâncias tóxicas os principais responsáveis por esse aumento, que subiram mais de 420\% (5.394 casos em 2007 e 22.809 casos em 2017). Em 2007, os acidentes por substâncias tóxicas representavam menos de $30 \%$ dos casos de intoxicação, enquanto os animais peçonhentos ficavam com mais de $70 \%$. Em 2017, essa diferença alterou-se bastante, com 46,1\% dos registros correspondendo aos acidentes com substâncias tóxicas. (GUMMIN et al. 2017; MINISTÉRIO DA SAÚDE, 2019).

O Brasil apresenta um padrão de substâncias tóxicas envolvidas nesses acidentes. Desses, três agentes concentram mais de $60 \%$ dos casos. De maneira geral os medicamentos representaram o primeiro lugar, com aproximadamente $30 \%$ dos casos, enquanto os animais peçonhentos ficaram em segundo lugar, com pouco mais de $20 \%$ e produtos de limpeza em terceiro, com menos de $12 \%$. O restante dos casos distribui-se de maneira equilibrada entre os demais agentes tóxicos (DOMINGOS, 2016; MINISTÉRIO DA SAÚDE, 2019).

\section{OBJETIVOS}

\subsection{OBJETIVO GERAL}

Caracterizar epidemiologicamente os casos de intoxicação exógena aguda por substâncias nocivas e por acidentes por animais peçonhentos em crianças de zero a 9 anos no Estado do Amapá no período de 2007 a 2017. 


\subsection{OBJETIVOS ESPECÍFICOS}

- Quantificar o total de casos de intoxicação exógena aguda por substâncias nocivas e por acidentes por animais peçonhentos em crianças de zero a 9 anos no Estado do Amapá no período de 2007 a 2017;

- Descrever o perfil epidemiológico dos casos registrados através das variáveis: ano de ocorrência, sexo, faixa etária, agente tóxico, circunstância, gravidade e desfecho clínico.

\section{MATERIAIS E MÉTODOS}

\subsection{TIPO DE ESTUDO}

Foi realizado um estudo epidemiológico, retrospectivo, descritivo com abordagem quantitativa de uma série histórica, no período de 2007 a 2017.

\subsection{CARACTERIZAÇÃO DA AMOSTRA E PERÍODO DO ESTUDO}

Foram utilizados dados secundários obtidos no endereço eletrônico do DATASUS ${ }^{7}$. Foi selecionado o item "Informações de Saúde (TabNet), Epidemiologia e Morbidade" e doravante a opção "Doenças e Agravos de Notificação - De 2007 em diante (SINAN - SISTEMA DE INFORMAÇÃO DE AGRAVOS DE NOTIFICAÇÃO)", escolhido o item Acidente por Animais Peçonhentos e Intoxicação Exógena e então foram estudadas as informações relativas ao Estado do Amapá de 2007 a 2017, com as variáveis ano de ocorrência, sexo, faixa etária, agente tóxico, circunstância, gravidade e desfecho clínico.

O período escolhido para o estudo (2007-2017) levou em consideração os dados mais recentemente disponíveis no TabNet. Dados de 2018 em diante ainda não estão disponíveis para consulta. 


\subsection{POPULAÇÃO ALVO}

Foram estudados dados secundários referentes a intoxicação exógena e acidentes por animais peçonhentos envolvendo crianças de zero a 9 anos registrados no Estado do Amapá.

O presente estudo teve como foco as crianças de zero a 9 anos, conforme as definições da OMS, uma vez que o avanço da idade implica em mudanças nos padrões comportamentais e consequentemente o padrão das intoxicações, especialmente em adolescentes, quando são incluídas as intoxicações não acidentais e as tentativas de suicídio. Além disso, o Departamento de Informática do Sistema Único de Saúde (DATASUS) agrupa os dados relacionados às intoxicações nas seguintes faixas etárias: menores de 1 ano, de 1 a 4 anos e de 5 a 9 anos. $O$ que permitiu a esse estudo, analisar de maneira fidedigna os dados relacionados às crianças de 0 a 9 anos.

\subsection{COLETA E ANÁLISE DE DADOS}

Os dados coletados do DATASUS foram registrados em planilhas do software Microsoft Excel 2010® para análise e elaboração de gráficos e tabelas.

\subsection{RISCOS E BENEFÍCIOS}

Nenhum dano associado ou decorrente da pesquisa - agravo imediato ou tardio, ao indivíduo ou à coletividade, com nexo causal comprovado, direto ou indireto, pode ser decorrente do estudo científico realizado, uma vez que todo o andamento da pesquisa foi acompanhado de perto pela equipe de trabalho, que utilizou dados secundários disponíveis online em um sistema público de informações.

O proveito advindo a partir deste estudo, que é tema pouco pesquisado no cenário proposto, poderá fornecer maiores informações sobre o atendimento ao paciente intoxicado ampliando os conhecimentos sobre este agravo e como consequência, a 
melhora dos serviços de pronto-atendimento, além de poder ser base para futuros estudos e políticas públicas na área.

\subsection{CRITÉRIOS DE INCLUSÃO E EXCLUSÃO}

Foram incluídos no estudo as notificações de intoxicações agudas e acidentes por animais peçonhentos envolvendo crianças de zero a 9 anos e excluídos os casos de intoxicações por alimentos e bebidas.

\subsection{ASPECTOS ÉTICOS}

O projeto foi inscrito na Plataforma Brasil e, portanto, submetido ao Comitê de Ética em Pesquisa da Universidade Federal do Amapá (UNIFAP) para obtenção de isenção do Termo de Consentimento Livre e Esclarecido (TCLE), considerando a Resolução № 466, de 12 de dezembro de 2012, uma vez que utilizou dados secundários disponíveis em um sistema de informações público-governamentais.

\section{RESULTADOS}

No Estado do Amapá, o total de casos intoxicação exógena notificados de 2007 a 2017 foi de 1015. Os anos de 2010 e 2011 apresentaram os menores número de casos, com 54 e 53 casos, respectivamente. Os últimos 5 anos registraram o maior número de casos, considerando todos os acidentes. $\mathrm{O}$ ano de 2017 apresentou o maior número de registros, com total de 139 casos. A distribuição de todos os casos de notificação exógena por substâncias químicas e animais peçonhentos, registrados de 2007 a 2017 no Estado do Amapá encontra-se no Quadro 1. 
Quadro 1. Distribuição dos casos de intoxicação exógena por substâncias químicas e animais peçonhentos em crianças de 0 a 9 anos, registrados de 2007 a 2017 no Estado do Amapá.

\begin{tabular}{|c|c|c|c|c|c|c|c|c|c|c|c|c|}
\hline Grupo de agentes & $\begin{array}{c}200 \\
7\end{array}$ & $\begin{array}{c}200 \\
8\end{array}$ & $\begin{array}{c}200 \\
9\end{array}$ & $\begin{array}{c}201 \\
0\end{array}$ & $\begin{array}{c}201 \\
1\end{array}$ & $\begin{array}{c}201 \\
2\end{array}$ & $\begin{array}{c}201 \\
3\end{array}$ & $\begin{array}{c}201 \\
4\end{array}$ & $\begin{array}{c}201 \\
5\end{array}$ & $\begin{array}{c}201 \\
6\end{array}$ & $\begin{array}{c}201 \\
7\end{array}$ & $\begin{array}{c}\text { Tota } \\
1\end{array}$ \\
\hline Substâncias químicas & 0 & 0 & 0 & 0 & 0 & 4 & 2 & 2 & 0 & 4 & 2 & 14 \\
\hline Ign/Branco & 0 & 0 & 0 & 0 & 0 & 1 & 0 & 1 & 0 & 0 & 0 & 2 \\
\hline Medicamento & 0 & 0 & 0 & 0 & 0 & 1 & 0 & 0 & 0 & 1 & 0 & 2 \\
\hline Raticida & 0 & 0 & 0 & 0 & 0 & 0 & 1 & 0 & 0 & 0 & 1 & 2 \\
\hline Prod. veterinário & 0 & 0 & 0 & 0 & 0 & 0 & 0 & 0 & 0 & 0 & 1 & 1 \\
\hline Prod. uso domiciliar & 0 & 0 & 0 & 0 & 0 & 1 & 1 & 0 & 0 & 0 & 0 & 2 \\
\hline Cosmético & 0 & 0 & 0 & 0 & 0 & 1 & 0 & 0 & 0 & 0 & 0 & 1 \\
\hline Prod. químico & 0 & 0 & 0 & 0 & 0 & 0 & 0 & 1 & 0 & 0 & 0 & 1 \\
\hline Outro & 0 & 0 & 0 & 0 & 0 & 0 & 0 & 0 & 0 & 3 & 0 & 3 \\
\hline Serpentes & 62 & 46 & 57 & 44 & 39 & 73 & 60 & 90 & 91 & 81 & 103 & 746 \\
\hline Bothrops & 35 & 25 & 32 & 29 & 20 & 43 & 32 & 46 & 45 & 42 & 62 & 411 \\
\hline Crotalus & 0 & 0 & 0 & 1 & 0 & 1 & 1 & 1 & 0 & 1 & 1 & 6 \\
\hline Micrurus & 0 & 1 & 0 & 0 & 0 & 1 & 0 & 1 & 0 & 0 & 0 & 3 \\
\hline Lachesis & 0 & 1 & 3 & 3 & 2 & 5 & 4 & 4 & 5 & 1 & 2 & 30 \\
\hline $\begin{array}{l}\text { Serpente não } \\
\text { peçonhenta }\end{array}$ & 0 & 0 & 0 & 1 & 0 & 0 & 0 & 0 & 0 & 0 & 1 & 2 \\
\hline Serpente Ign/Branco & 27 & 19 & 22 & 10 & 17 & 23 & 23 & 38 & 41 & 37 & 37 & 294 \\
\hline Aranhas & 3 & 0 & 1 & 0 & 1 & 0 & 2 & 1 & 3 & 3 & 7 & 21 \\
\hline Phoneutria & 0 & 0 & 0 & 0 & 0 & 0 & 2 & 0 & 0 & 0 & 0 & 2 \\
\hline Loxosceles & 0 & 0 & 0 & 0 & 0 & 0 & 0 & 0 & 1 & 0 & 0 & 1 \\
\hline Latrodectus & 0 & 0 & 0 & 0 & 0 & 0 & 2 & 0 & 0 & 0 & 0 & 2 \\
\hline Outra espécie de aranha & 0 & 0 & 0 & 0 & 0 & 0 & 0 & 0 & 1 & 2 & 3 & 6 \\
\hline Aranha Ign/Branco & 3 & 0 & 1 & 0 & 1 & 0 & 0 & 1 & 1 & 1 & 2 & 10 \\
\hline Escorpião & 18 & 16 & 18 & 9 & 12 & 19 & 19 & 31 & 33 & 21 & 26 & 222 \\
\hline Lagarta & 0 & 0 & 1 & 1 & 1 & 1 & 0 & 0 & 0 & 2 & 1 & 7 \\
\hline Abelha & 0 & 0 & 0 & 0 & 0 & 0 & 0 & 0 & 0 & 0 & 0 & 0 \\
\hline Outros animais & 1 & 1 & 0 & 0 & 0 & 1 & 0 & 0 & 0 & 2 & 0 & 5 \\
\hline Total & 84 & 63 & 77 & 54 & 53 & 98 & 83 & 124 & 127 & 113 & 139 & 1015 \\
\hline
\end{tabular}

Fonte: DATASUS, 2019.

\subsection{DISTRIBUIÇÃO DE CASOS CONFORME O SEXO}

Observa-se na Tabela 1 que os meninos apresentam número de casos muito maior em relação às meninas, tanto nos casos de intoxicação por substâncias químicas ( $71,43 \%$ dos casos) quanto nos casos de acidentes por animais peçonhentos $(64,1 \%)$. 
Tabela 1. Distribuição dos casos de intoxicação por sexo em crianças de 0 a 9 anos, registrados entre 2007 a 2017 no Estado do Amapá.

\begin{tabular}{|l|l|l|l|l|l|}
\hline Agente Tóxico & \multicolumn{2}{|l|}{ Masculino } & \multicolumn{2}{|l|}{ Feminino } & Total \\
\hline & $n$ & $\%$ & $n$ & $\%$ & \\
\hline Substâncias químicas & 10 & 71,43 & 4 & 28,57 & 14 \\
\hline Animais peçonhentos & 641 & 64,1 & 359 & 35,9 & 1000 \\
\hline
\end{tabular}

Fonte: DATASUS, 2019.

A Figura 1 permite visualizar com facilidade a diferença entre o número de casos de intoxicações em meninos e meninas.

Figura 1. Porcentagem dos casos de intoxicação conforme o sexo em crianças de 0 a 9 anos registrados entre 2007 a 2017, no Estado do Amapá.

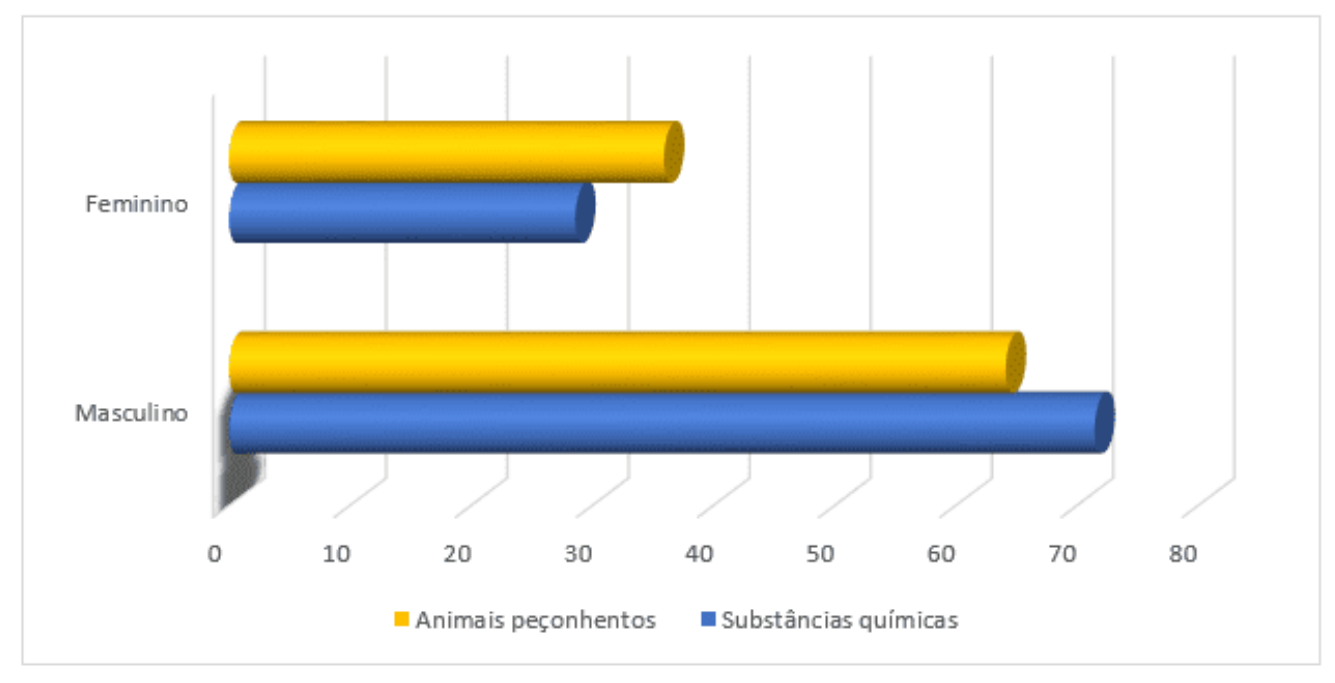

Fonte: DATASUS, 2019.

\subsection{DISTRIBUIÇÃO DE CASOS CONFORME O AGENTE CAUSADOR}

Verifica-se, conforme apresentado na Tabela 2, que a grande maioria do número de casos de intoxicação está relacionado aos acidentes animais peçonhentos, sendo o primeiro lugar por serpentes (73,5\% dos casos), seguido pelos casos de acidentes por 
escorpiões (21,87\%), em seguida, porém já com números bem menores, os acidentes por aranhas $(2,07 \%)$.

Tabela 2. Distribuição do total de casos de intoxicação exógena por substâncias químicas e animais peçonhentos, registrados de 2007 a 2017 no Estado do Amapá.

\begin{tabular}{|l|l|l|}
\hline Tipo de exposição & $\mathrm{n}$ & $\%$ \\
\hline Serpente & 746 & 73,50 \\
\hline Escorpião & 222 & 21,87 \\
\hline Aranha & 21 & 2,07 \\
\hline Substâncias químicas & 14 & 1,38 \\
\hline Lagarta & 7 & 0,69 \\
\hline Outros animais & 5 & 0,49 \\
\hline Total & 1015 & 100 \\
\hline
\end{tabular}

Fonte: DATASUS, 2019.

A Figura 2 mostra com mais clareza a discrepância entre o número de casos de acidentes por serpentes e os demais casos de intoxicação.

Figura 2. Distribuição dos casos de intoxicação exógena por substâncias químicas e animais peçonhentos, registrados de 2007 a 2017 no Estado do Amapá.

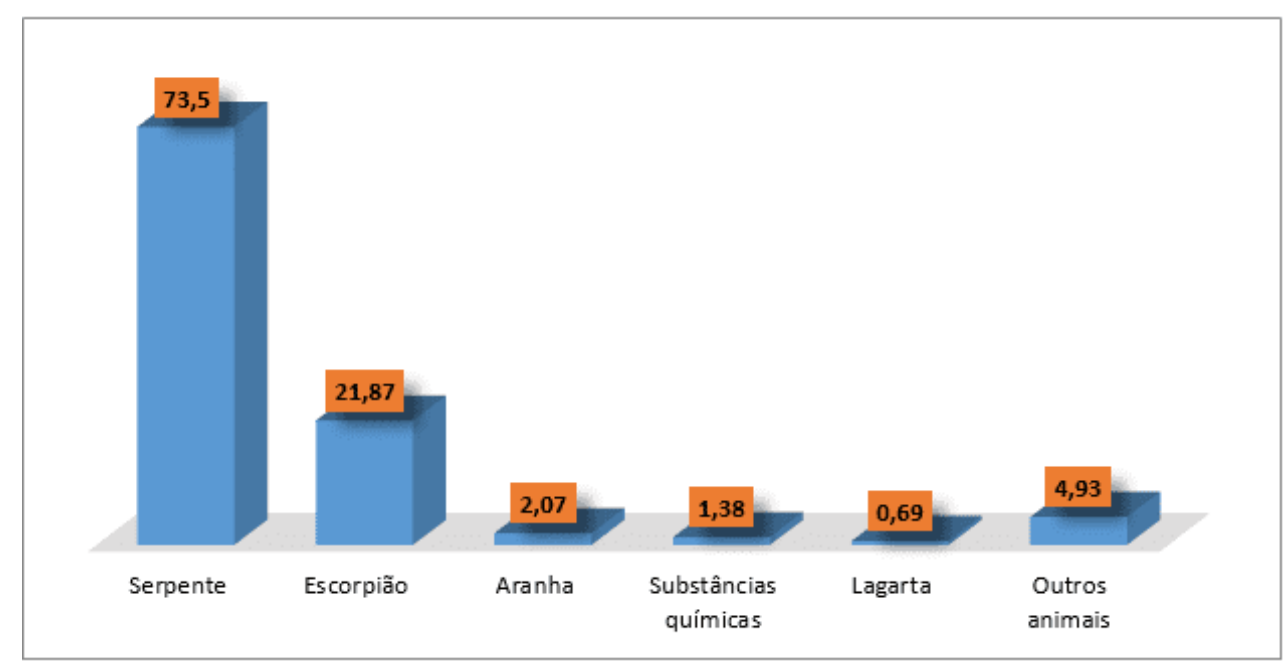

Fonte: DATASUS, 2019. 
A Tabela 3 apresenta a distribuição dos tipos de agente relacionados a cada caso de intoxicação. Observa-se que em relação às substâncias tóxicas, não houve diferença entre as intoxicações causadas por medicamentos, raticidas e produtos de uso domiciliar durante os 10 anos estudados.

Tabela 3. Distribuição dos casos de intoxicação exógena por substâncias químicas e animais peçonhentos, registrados de 2007 a 2017 no Estado do Amapá.

\begin{tabular}{|l|l|l|}
\hline Tipo de exposição & Total & $\%$ \\
\hline Substâncias químicas & 14 & \\
\hline Ign/Branco & 2 & $14,29 \%$ \\
\hline Medicamento & 2 & $14,29 \%$ \\
\hline Raticida & 2 & $14,29 \%$ \\
\hline Prod. uso domiciliar & 2 & $14,29 \%$ \\
\hline Prod. veterinário & 1 & $7,14 \%$ \\
\hline Cosmético & 1 & $7,14 \%$ \\
\hline Prod. químico & 1 & $7,14 \%$ \\
\hline Outro & 3 & $21,43 \%$ \\
\hline Animais peçonhentos & 1000 & \\
\hline Serpente & 746 & $74,6 \%$ \\
\hline Escorpião & 222 & $22,2 \%$ \\
\hline Aranha & 21 & $21,0 \%$ \\
\hline Lagarta & 7 & $7,0 \%$ \\
\hline Abelha & 0 & $0,0 \%$ \\
\hline Outros animais & 5 & $5,0 \%$ \\
\hline & & \\
\hline
\end{tabular}

Fonte: DATASUS, 2019.

Já a relação de tipos de agente relacionados aos animais peçonhentos apresenta diferença importante, sendo as serpentes os animais mais incidentes (746 casos), seguidos de escorpiões (222 casos) e aranhas com número bem menor (21 casos). Não houve registros de casos de acidentes por abelha no período estudado. 
Com relação aos acidentes por serpentes, no Estado do Amapá verificou-se que o gênero Bothrops foi o que causou maior número de acidentes no período analisado, 411 casos, seguidos em menor número pelo gênero Lachesis, com 30 casos e Crotalus, 6 casos, conforme apresentado na Tabela 4. Dos 3 casos reportados de acidentes por Micrurus, houve um para cada faixa etária pesquisada (menores de 1 ano, 1 a 4 anos e 5 a 9 anos).

Importante observar o grande número casos em que a espécie foi ignorada ou deixada em branco durante a notificação do acidente (294 casos).

Tabela 4. Número de casos de acidentes por gênero de serpentes em crianças de 0 a 9 anos registrados entre 2007 a 2017, no Estado do Amapá.

\begin{tabular}{|l|l|l|}
\hline Serpente & $\mathrm{n}$ & $\%$ \\
\hline Bothrops & 411 & $55,1 \%$ \\
\hline Espécie Ignorada ou em branco & 294 & $39,4 \%$ \\
\hline Lachesis & 30 & $4,02 \%$ \\
\hline Crotalus & 6 & $0,8 \%$ \\
\hline Micrurus & 3 & $0,4 \%$ \\
\hline Serpente não peçonhenta & 2 & $0,3 \%$ \\
\hline
\end{tabular}

Fonte: DATASUS, 2019.

A Figura 3 permite melhor visualização da distribuição de casos de intoxicação exógena por substância tóxica no período avaliado. 
Figura 3. Distribuição dos casos de intoxicação exógena por substância química em crianças de 0 a 9 anos registrados entre 2007 a 2017, no Estado do Amapá.

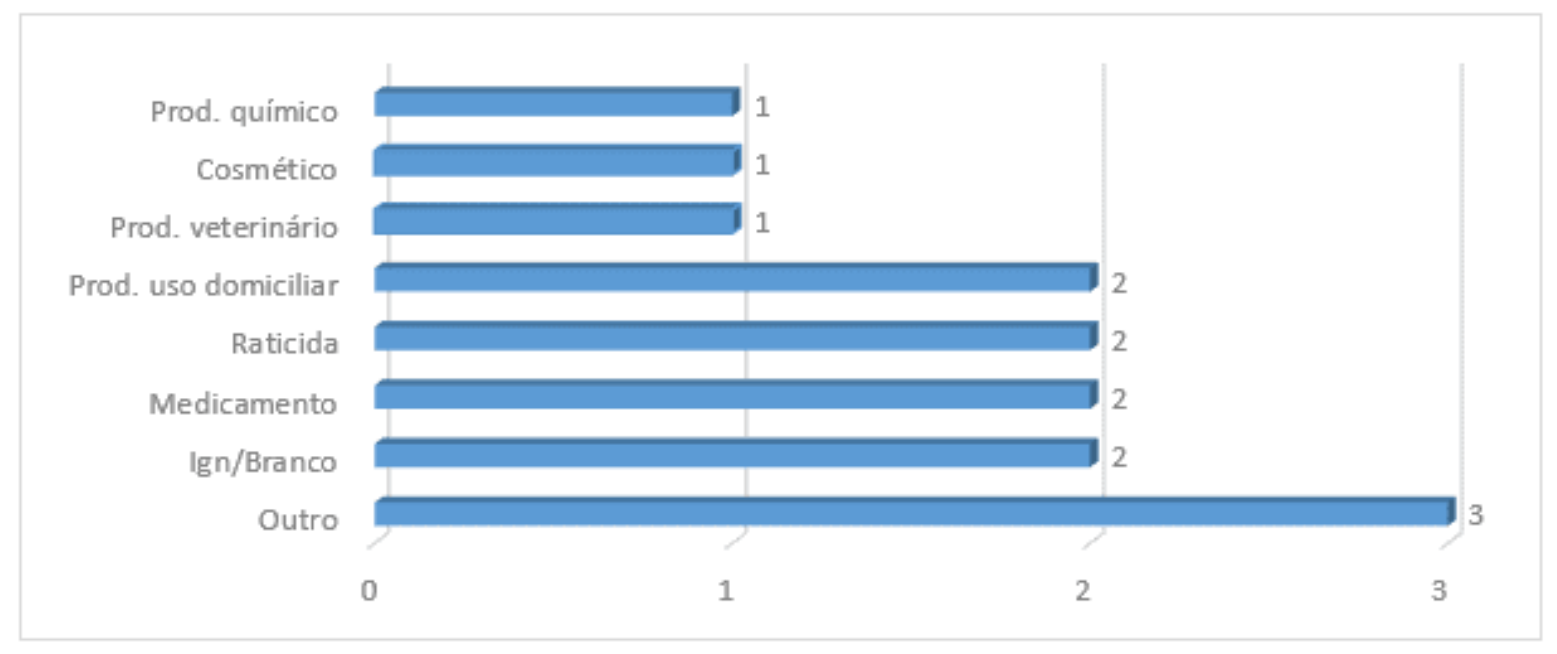

Fonte: DATASUS, 2019.

A Figura 4 permite melhor visualização da distribuição de casos de acidentes por tipo de aranha no período avaliado.

Figura 4. Distribuição dos casos de acidentes causados por aranhas em crianças de 0 a 9 anos registrados entre 2007 a 2017, no Estado do Amapá.

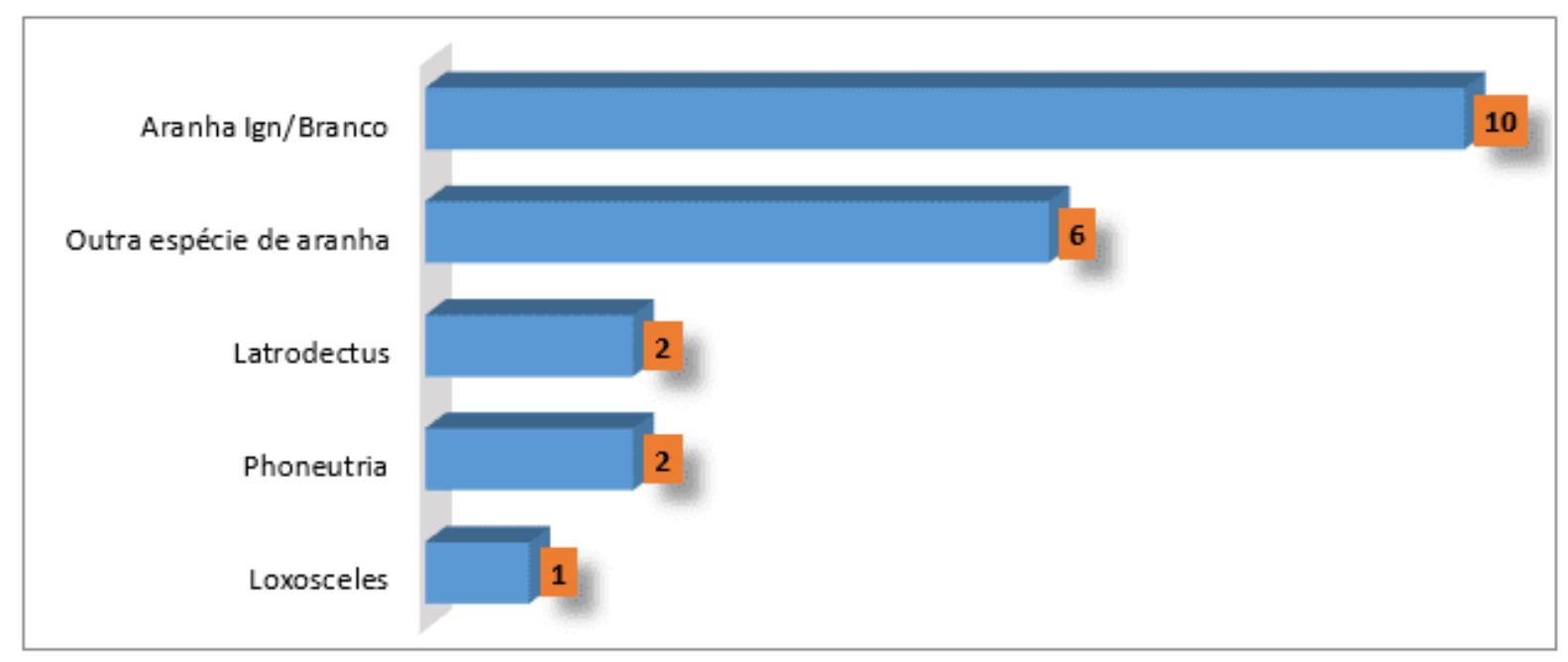

Fonte: DATASUS, 2019. 
O sistema DATASUS não permite a classificação dos acidentes por escorpiões e lagartas conforme o gênero ou espécie. Não permite também incluir qual tipo de medicamento foi causador da intoxicação por substância tóxica.

\subsection{DISTRIBUIÇÃO DE CASOS CONFORME GRAVIDADE E DESFECHO CLÍNICO}

A maioria dos casos de acidentes por animais peçonhentos foi classificada como acidentes leves (401 casos), sendo que mais da metade deles (235 casos) aconteceram em crianças de 5 a 9 anos. Esses dados estão agrupados no Quadro 2, a seguir.

Foram registrados 22 casos de acidentes graves em crianças, sendo 18 causados por serpentes. Não houve notificação de casos graves relacionados à crianças menores de 1 ano no período estudado. Mais de $1 / 4$ dos acidentes (117 casos) não foi classificado quando sua gravidade ou teve a classificação ignorada.

O sistema do DATASUS não permite classificar os casos de intoxicação por substâncias químicas quanto a sua gravidade.

Quadro 2. Distribuição de casos de acidente por animais peçonhentos de acordo com a gravidade e faixa etária em crianças de zero a 9 anos registrados de 2007 a 2017 no Estado do Amapá.

\begin{tabular}{|l|l|l|l|l|l|l|l|}
\hline & & Serpente & Aranha & Escorpião & Lagarta & Outros & Total \\
\hline Leve & $<\mathbf{1}$ ano & 48 & 1 & 12 & 0 & 0 & 61 \\
\hline $\begin{array}{l}\mathbf{1} \text { a } \mathbf{4} \\
\text { anos }\end{array}$ & 51 & 8 & 44 & 2 & 0 & 105 \\
\hline $\begin{array}{l}\mathbf{5} \text { a } \mathbf{9} \\
\text { anos }\end{array}$ & 166 & 7 & 55 & 3 & 4 & 235 \\
\hline Moderado & $<\mathbf{1}$ ano & 18 & 2 & 12 & 0 & 0 & 32 \\
\hline
\end{tabular}




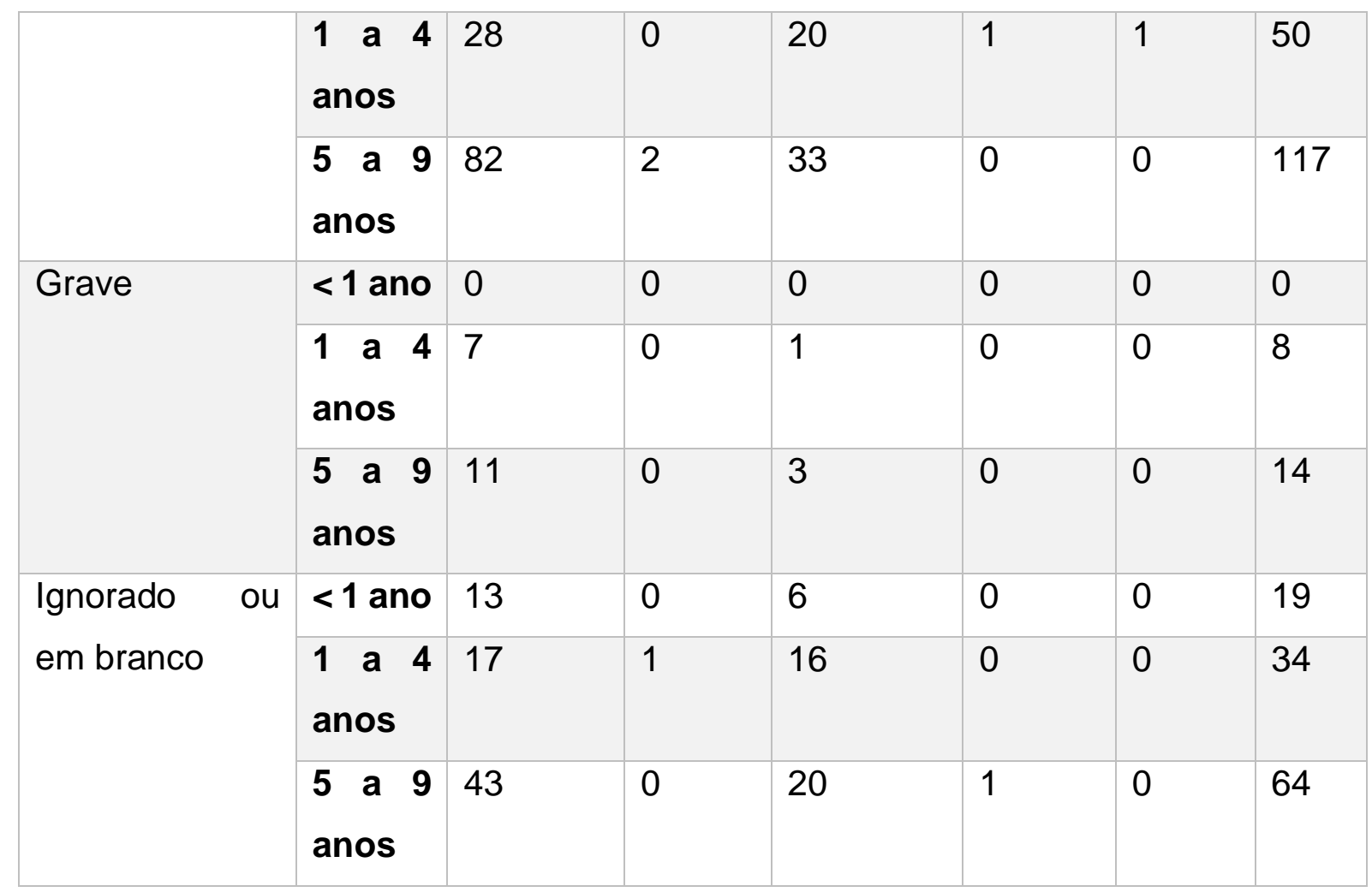

Fonte: DATASUS, 2019.

A Figura 5 a seguir permite melhor visualização e comparação da gravidade dos casos de acidente por animais peçonhentos. É possível identificar que os casos de acidentes por aranha, lagarta e outros são de natureza leve ou moderada. Já os casos graves se distribuem entre os acidentes por serpentes e escorpiões. 
Figura 5. Distribuição de casos de acidentes por animais peçonhentos conforme gravidade e faixa etária, em crianças de 0 a 9 anos no período de 2007 a 2017, no Estado do Amapá.

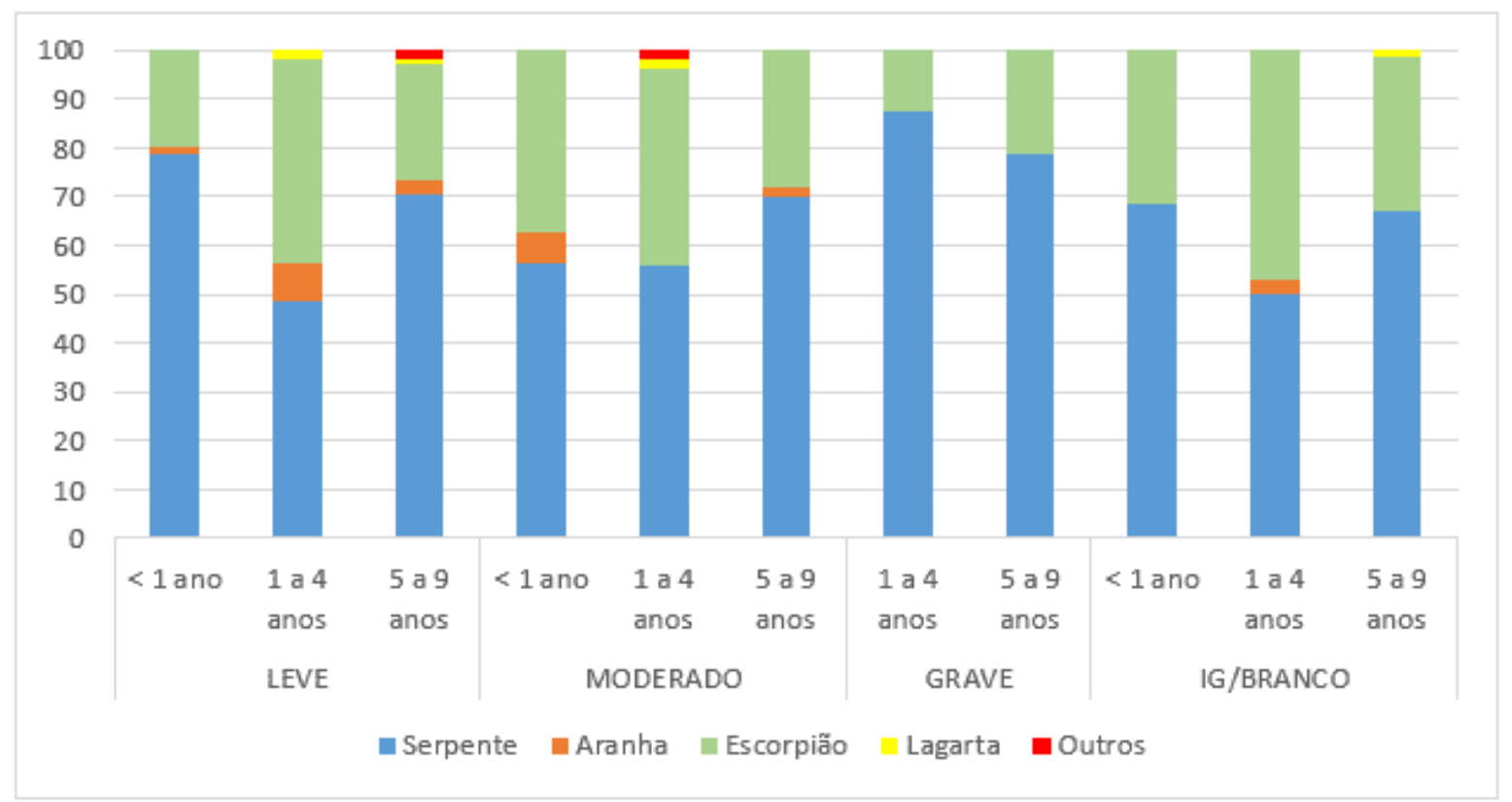

Fonte: DATASUS, 2019.

Todos os casos de intoxicação por animais peçonhentos e por substâncias químicas, no período de 2007 a 2007 foram registrados com desfecho clínico "cura sem sequela", independente do sexo analisado. Não foi registrado nenhum óbito relacionado às intoxicações exógenas no período analisado.

\subsection{DISTRIBUIÇÃO DOS CASOS AO LONGO DO ANO}

Em relação à sazonalidade das intoxicações, observa-se na Figura 6, que no Amapá o maior número de casos aconteceu no mês de setembro (36\% dos casos), seguido por números menores em Junho (15\%) e Outubro (14\%). 
Figura 6. Distribuição mensal dos acidentes por substâncias tóxicas em crianças de 0 a 9 anos registrados entre 2007 a 2017, no Estado do Amapá.

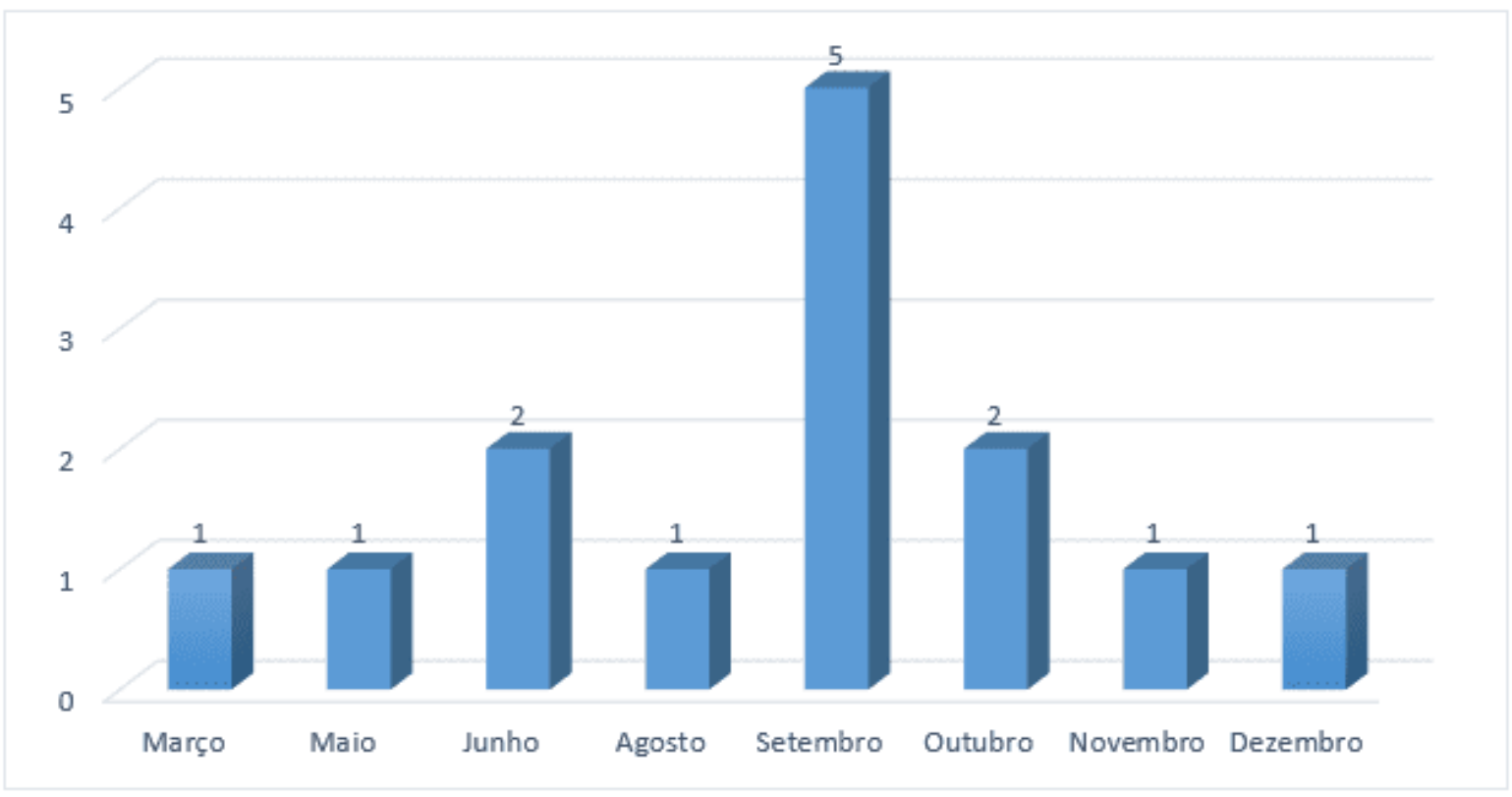

Fonte: DATASUS, 2019.

Em relação aos acidentes por animais peçonhentos, tanto os acidentes por serpentes quanto os acidentes causados pelos demais animais, aconteceram em maioria no mês de Junho, sendo que em ambos os casos, o primeiro semestre do ano concentrou o maior número dos casos.

A Figura 7 mostra que em Junho foram registrados $16 \%$ dos acidentes por animais peçonhentos, excluindo-se as serpentes, seguidos pelos meses de Maio e Agosto, ambos com $11 \%$. 
Figura 7. Distribuição anual dos acidentes por acidentes por animais peçonhentos, excluindo-se as serpentes, em crianças de 0 a 9 anos registrados entre 2007 a 2017, no Estado do Amapá.

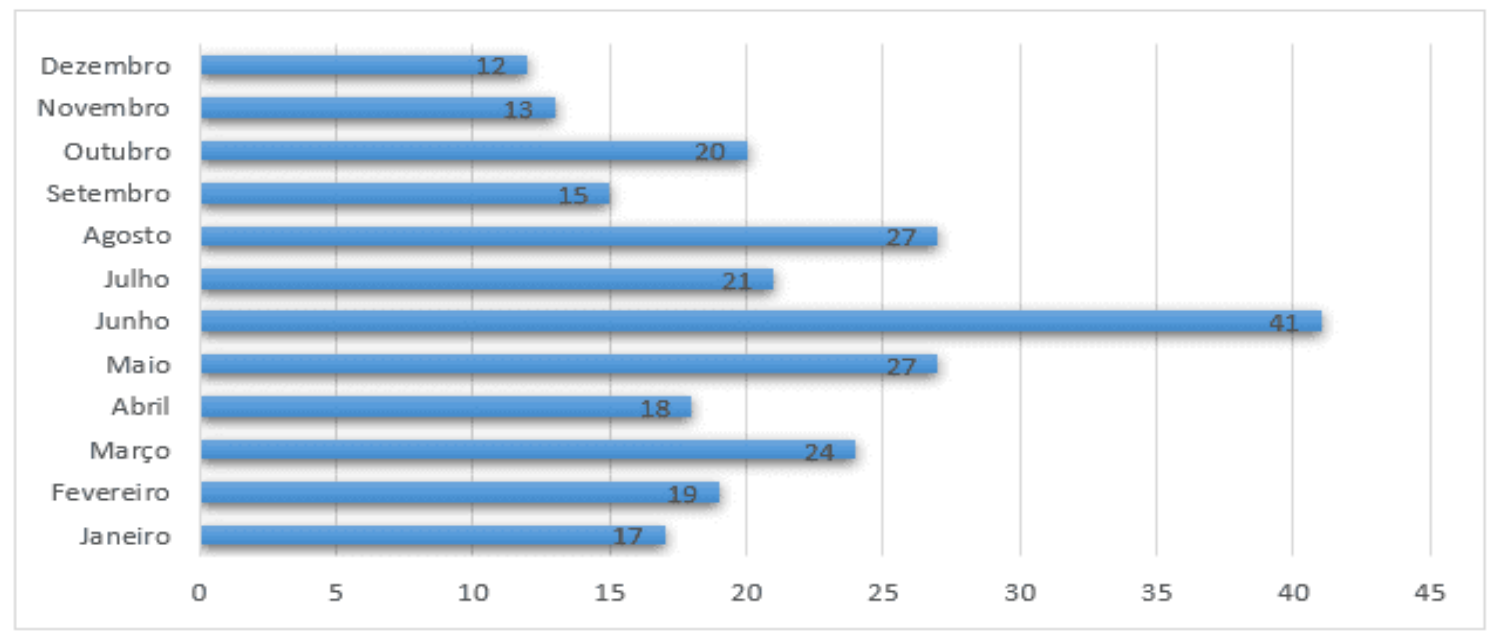

Fonte: DATASUS, 2019.

Os acidentes por serpentes aconteceram em maior número em Junho (12\%) seguido dos meses de Março (10\%), e Maio e Julho, ambos com 9\% dos casos, como observado na Figura 8.

Figura 8. Distribuição anual dos acidentes por acidentes serpentes, em crianças de 0 a 9 anos registrados entre 2007 a 2017, no Estado do Amapá.

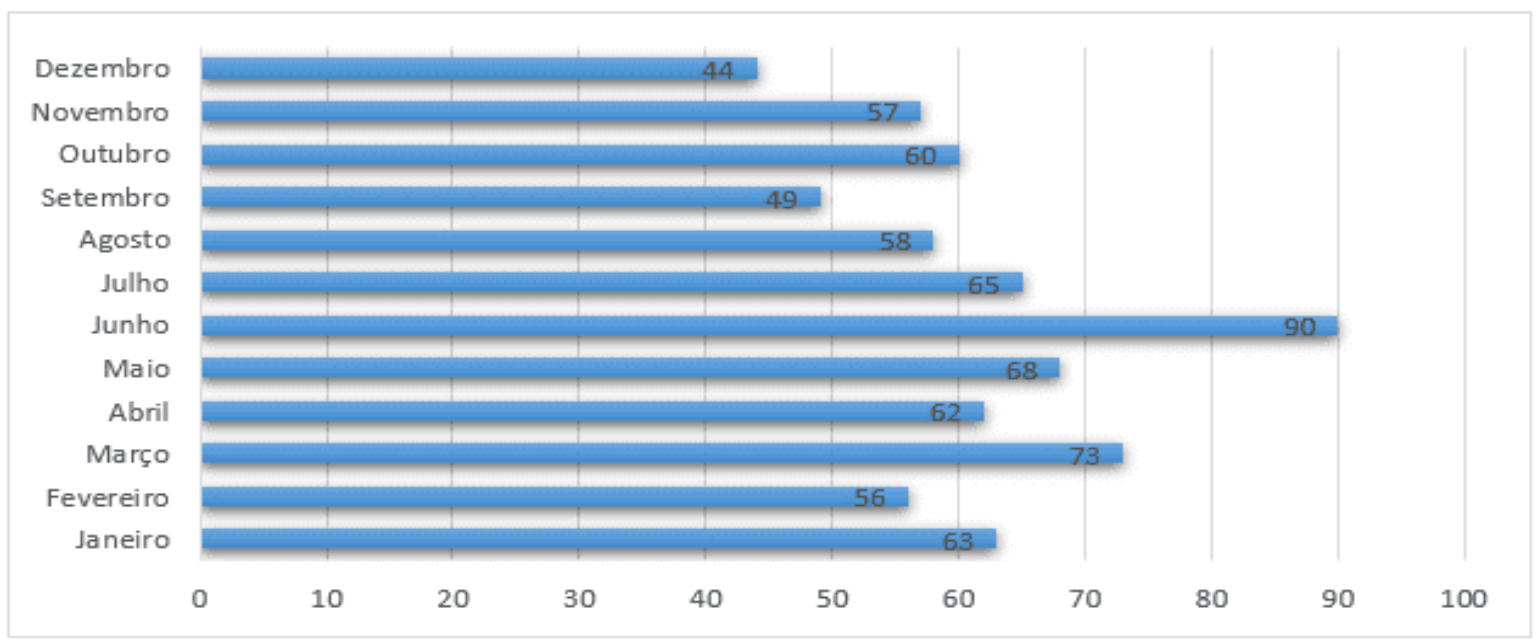

Fonte: DATASUS, 2019. 


\subsection{DISTRIBUIÇÃO DE CASOS CONFORME FAIXA ETÁRIA}

A Tabela 5 a seguir mostra o número de acidentes por animais peçonhentos, conforme a faixa etária. Observa-se que as crianças entre 5 e 9 anos apresentam maior número de casos (430 casos), seguidas pelas crianças de 1 a 4 anos (197 casos). O número de crianças menores de 1 ano que sofreram intoxicação por animal peçonhento foi de 112 nos 10 anos estudados.

Tabela 5. Casos de acidentes por animais peçonhentos conforme faixa etária, em crianças de 0 a 9 anos no período de 2007 a 2017, no Estado do Amapá.

\begin{tabular}{|l|l|l|l|}
\hline Animal peçonhento & $<1$ ano & 1 a 4 anos & 5 a 9 anos \\
\hline Serpente & 79 & 103 & 302 \\
\hline Aranha & 3 & 9 & 9 \\
\hline Escorpião & 30 & 81 & 111 \\
\hline Lagarta & 0 & 3 & 4 \\
\hline Outros & 0 & 1 & 4 \\
\hline Total & 112 & 197 & 430 \\
\hline
\end{tabular}

Fonte: DATASUS, 2019.

A Figura 9 mostra de maneira clara a distribuição dos casos de acidentes por animais peçonhentos conforme a faixa etária. 
Figura 9. Distribuição de casos de acidentes por animais peçonhentos conforme faixa etária, em crianças de 0 a 9 anos no período de 2007 a 2017, no Estado do Amapá.

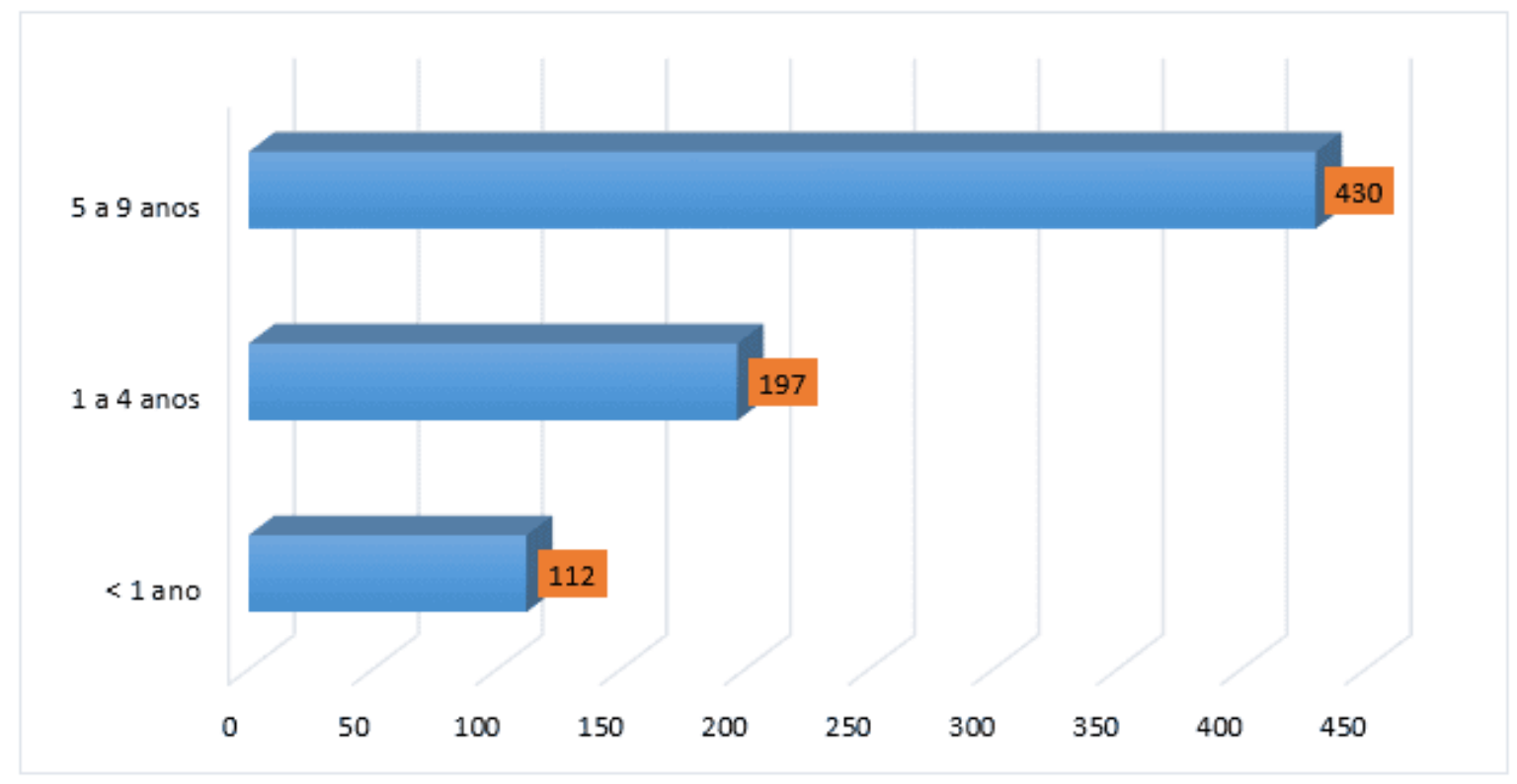

Fonte: DATASUS, 2019.

A Tabela 6 mostra o número de acidentes com substâncias nocivas, conforme a faixa etária. Observa-se que as crianças entre 1 a 4 anos apresentam maior número de casos (8 casos), seguidas pelas crianças menores de 1 ano (5 casos). Houve apenas 1 caso registrado de crianças entre 5 e 9 anos que sofreu intoxicação por substâncias químicas no período de 10 anos.

Tabela 6. Casos de intoxicação por substâncias nocivas conforme faixa etária, em crianças de 0 a 9 anos no período de 2007 a 2017, no Estado do Amapá.

\begin{tabular}{|l|l|l|l|}
\hline Substância química & $<1$ ano & 1 a 4 anos & 5 a 9 anos \\
\hline Medicamentos & 0 & 2 & 0 \\
\hline Raticidas & 2 & 0 & 0 \\
\hline Prod. Veterinário & 0 & 1 & 0 \\
\hline Prod. uso domiciliar & 0 & 2 & 0 \\
\hline Cosmético & 1 & 0 & 0 \\
\hline Prod. Químico & 0 & 0 & 1 \\
\hline
\end{tabular}




\begin{tabular}{|l|l|l|l|}
\hline Outro & 1 & 2 & 0 \\
\hline Ignorado ou em branco & 1 & 1 & 0 \\
\hline Total & $\mathbf{5}$ & $\mathbf{8}$ & $\mathbf{1}$ \\
\hline
\end{tabular}

Fonte: DATASUS, 2019.

A Figura 10 mostra de maneira clara a distribuição dos casos de acidentes por substâncias tóxicas conforme a faixa etária.

Figura 10. Distribuição de casos de acidentes por substâncias tóxicas conforme faixa etária, em crianças de 0 a 9 anos no período de 2007 a 2017, no Estado do Amapá.

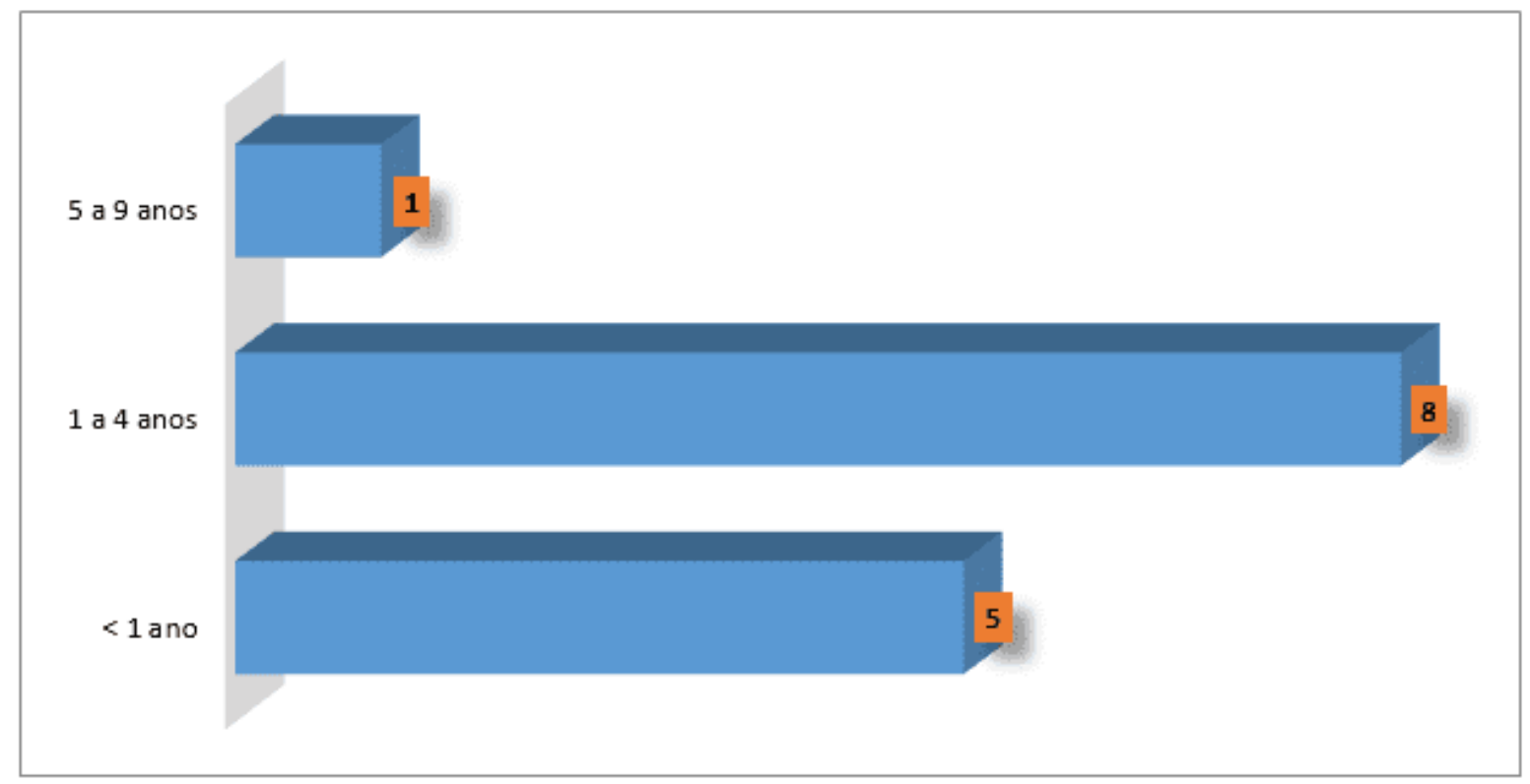

Fonte: DATASUS, 2019.

\subsection{DISTRIBUIÇÃO DE CASOS DE INTOXICAÇÃO POR SUBSTÂNCIAS CONFORME A CIRCUNSTÂNCIA DO EVENTO}

Em relação à circunstância do acidente por substâncias tóxicas, em 2007 foi registrado 1 caso de tentativa de suicídio com uso de substância química por criança menor de 1 ano. Não estão registrados outros tipos de circunstâncias nem para intoxicação por animais peçonhentos nem por substâncias químicas. 


\section{DISCUSSÃO}

\subsection{QUANTO AO SEXO}

Crianças do sexo masculino foram mais acometidas por acidentes envolvendo tanto substâncias tóxicas quanto animais peçonhentos no estado amapaense, informação que está em conformidade com pesquisas a nível nacional e mundial (BRITO, 2015; DOMINGOS 2016).

Aspectos comportamentais, sociais e culturais podem justificar os valores superiores nos acidentes envolvendo meninos, uma vez que estes costumam ser menos supervisionados em suas atividades ao ar livre em relação às meninas, sendo corriqueiramente mais agitados e se arriscam mais em suas atividades lúdicas (BRITO, 2015; DOMINGOS 2016).

\subsection{DISTRIBUIÇÃO DE CASOS CONFORME O AGENTE CAUSADOR}

Serpentes foram as causadoras da maioria das intoxicações em crianças no estado do Amapá, diferindo dos dados esperados, cujo acidente com escorpiões foram os responsáveis pela maioria dos casos de intoxicação no Brasil, com 60.370 casos por ano (SILVA, 2015).

O gênero Bothrops foi o maior responsável pelos acidentes ofídicos no estado do Amapá, dado que concorda com os dados dos demais estados brasileiros, sendo que esses acidentes representam mais de $73 \%$ dos casos (SILVA, 2015).

No Amapá, o acidente laquético é o segundo em número de notificações e com 30 casos registrados no período. As serpentes do gênero Lachesis, conhecidas como surucucu, são comumente encontradas em áreas de floresta densa, o que provavelmente justifica os casos em nossa região amazônica. Apenas três casos com corais-verdadeiras (Micrurus spp) foram registrados entre crianças amapaenses no período estudado, curiosamente, um para cada faixa etária pesquisada. As cores 
vivas desse gênero e seus anéis podem ser o motivo da atração das crianças, causando os acidentes (SILVA, 2015; BRASIL, 2001).

As notificações por acidentes escorpiônicos são as que mais aumentaram em número nos últimos anos no Brasil. Os casos registrados no Amapá seguiram o padrão observado nos estudos realizados nas demais regiões, com o número crescente de casos no período estudado, sendo 2014 e 2015 os anos com mais casos catalogados. A faixa etária de 5 a 9 anos foi a mais frequentemente acometida por acidentes com escorpiões. Segundo estudos, crianças e adolescentes representam o grupo de maior risco quanto ao óbito nesse tipo de acidente (CANTINHO, 2016; SILVA, 2015). O sistema do DATASUS não permite a classificação dos acidentes de acordo o a espécie de escorpião.

Em relação ao araneísmo, dentre os gêneros registrados, as Latrodectus e as Phoneutria foram as com maior número de casos no estado do Amapá. Comparandose ao número de ocorrências no Brasil, o gênero Latrodectus fica em terceiro lugar. O gênero Phoneutria, espécie conhecida como "armadeira", ocupa o segundo lugar em número de acidentes no Brasil. O primeiro lugar no Brasil é ocupado pela Loxosceles, conhecida popularmente como "aranha marrom" (SILVA, 2015; BRASIL, 2001).

Foram registrados sete casos de intoxicação em episódios com lagartas no estado do Amapá, três casos envolvendo crianças na faixa etária de 1 a 4 anos e 4 casos entre crianças de 5 a 9 anos, nenhum caso em menores de 1 ano. $O$ primeiro semestre do ano, assim como com os demais animais peçonhentos, foi o de maior ocorrência dos casos, sendo julho o mês com mais registros, 3 casos. No Brasil, as lagartas do gênero Lonomia são os animais de importância médica, por conta das complicações hemorrágicas que podem acontecer (BRASIL, 2001, CHEUNG, 2017).

Quanto aos acidentes com abelhas, não houve nenhum registro de casos na faixa etária pesquisada no período compreendido entre 2007 a 2017. Um possível motivo para isso seja a baixa procura por atendimento médico nesses casos, a não ser diante de um quadro clínico mais exuberante, como reações alérgicas a picada de abelhas, o que não costuma ser frequente em crianças, mas sim em adultos (CHEUNG, 2017). 
Os casos de intoxicação por substâncias químicas começaram a ser registrados no Amapá em 2012 e desde então as notificações anuais vem se mantendo baixos, com 4 casos em 2016 e 2 em 2017. O número baixo de registro de intoxicação por substâncias exógenas está em desacordo com os dados nacionais, uma vez que nos últimos anos têm havido aumento progressivo das notificações ao Sistema de Informação de Agravos de Notificação (SINAN). Só em 2002 foram notificadas 75.212 exposições sendo $25,4 \%$ em crianças com menos de 5 anos de idade (BUCARETCHI \& BARACAT, 2005). Segundo estudos, o aumento nessas notificações ocorre devido ao aumento do número de casos de intoxicação por substâncias químicas. (AMORIM, 2017; BRITO, 2015; WHO, 2008)

Os agentes causadores mais reportados no presente estudo foram raticidas, medicamentos e domissanitários com 2 registros em cada uma das classes. Houve também dois casos cujos agentes foram "ignorados ou em branco", o que reduz a precisão de estudos epidemiológicos. Crianças menores de 1 ano de idade foram as mais suscetíveis aos acidentes com raticidas, uma vez que do total de 14 registros de acidentes com substâncias exógenas no Amapá, essa faixa etária foi a única em que houve casos. Os agravos com medicamentos e domissanitários tiveram casos registrados apenas entre crianças de 1 a 4 anos. A maior frequência de intoxicações causadas por pesticidas em menores de 1 ano e a maior frequência de intoxicação por produtos de uso doméstico na faixa etária de 1 a 4 ano estão de acordo com os achados de Brito (2015).

A pequena quantidade de notificações de intoxicações exógenas no período de 2007 a 2017 no estado do Amapá pode sugerir que muitos casos não foram reportados aos registros do SINITOX. Uma possível justificativa pode ser a dificuldade de acesso da população aos serviços de saúde, já que o Estado possui grandes áreas de acesso remoto sendo habitadas. Tal fato reforça a importância de disseminar campanhas educativas sobre primeiros socorros e ao mesmo tempo oferecer treinamento profissional e assistência, bem como a implantação do serviço de atendimento especializado do CEATOX no Estado. (SILVA, 2015; WHO, 2007). 


\subsection{DISTRIBUIÇÃO DE CASOS CONFORME GRAVIDADE E DESFECHO CLÍNICO}

O sistema DATASUS permite classificar o desfecho final de todos os acidentes em: cura sem sequela, cura com sequela, óbito por intoxicação, óbito por outra causa e perda do seguimento. $O$ desfecho de todos os casos de intoxicação por substâncias e acidentes por peçonhentos reportados durante os 10 anos estudados pelo presente trabalho foi a cura sem sequelas. Não houve registro de nenhum óbito (MINISTÉRIO DA SAÚDE, 2019).

Sabe-se que os casos de intoxicação por substâncias químicas nessa faixa etária geralmente acontecem de forma acidental, o que confere ao acidente um padrão de baixa morbimortalidade (GUMMIN et al. 2017). A despeito disso, no ano de 2002 foram registrados no Brasil 375 óbitos causados por intoxicação por substâncias tóxicas, sendo 31 em crianças com menos de 5 anos de idade (BUCARETCHI \& BARACAT, 2005).

Já os acidentes por animais peçonhentos podem apresentar maiores repercussões clínicas, uma vez que as complicações do acidente se relacionam com a massa corporal do acidentado e à quantidade de veneno inoculada. Destacam-se dentre as complicações, as hemorragias, insuficiência renal aguda, edema agudo de pulmão e choque, podendo evoluir ao óbito

Nos Estados Unidos da América (EUA), os medicamentos são aos agentes tóxicos com maior causa de internação e letalidade ao lado dos acidentes com animais peçonhentos (DOMINGOS 2016; GUMMIN, 2017).

\subsection{QUANTO À SAZONALIDADE}

No período de 2007 a 2017, constatou-se maior número de notificações de acidentes por animais peçonhentos nos primeiros 6 meses do ano. Esse achado, está de acordo com o que sugerem outros pesquisadores, mostrando que a maior parte dos acidentes com animais peçonhentos acontece no decorrer dos meses mais quentes e chuvosos, 
o que permite a fartura de alimentos e o maior número de animais circulando no ambiente (CANTINHO, 2016; MESCHIAL, 2013; BRASIL, 2001).

Quanto às intoxicações por substâncias químicas no Amapá no período, a grande maioria ocorreu no mês de setembro. Uma hipótese anterior à coleta dos dados era de que durante os meses de férias escolares as crianças ficassem mais vulneráveis ao contato com agentes tóxicos por passarem mais tempo em casa uma vez que esse padrão foi descrito por Fontanele, et al (2015). Já nos meses de janeiro e julho, ao contrário do esperado, não foram notificados quaisquer agravos.

\subsection{DISTRIBUIÇÃO DE CASOS CONFORME FAIXA ETÁRIA}

O presente estudo identificou que os acidentes com animais peçonhentos foram mais prevalentes na faixa etária entre 5 e 9 anos, aspecto também observado em outras regiões do Brasil. Observou-se que com o aumento da idade, os casos de intoxicação entre as crianças amapaenses quase que duplicaram. Em relação às crianças menores de 1 ano, foram notificados 112 casos de acidentes por animais peçonhentos, sendo 79 casos de acidentes ofídicos. Trata-se de um dado muito alarmante, pois os acidentes causados por serpentes podem ter repercussões gravíssimas em crianças muito pequenas (AMORIM, 2017; BRASIL, 2001; DOMINGOS, 2016).

Quanto às intoxicações exógenas, as ocorrências foram mais frequentes entre crianças de 1 a 4 anos, conforme o esperado. Diversos trabalhos têm demonstrado que crianças nessa faixa etária estão mais suscetíveis às intoxicações, uma vez que o início da deambulação e o despertar da curiosidade pela exploração do ambiente agora passam a ser mais oportunos. Se sob uma supervisão adulta baixa, a criança pode estar mais exposta aos acidentes dentro e fora da residência. Pode-se suspeitar que os menores de 1 ano ainda não são capazes de se locomover e alcançar substâncias bem guardadas. Além disso, as crianças de 5 a 9 anos têm maior capacidade de diferenciar aquilo que lhes faz mal, evitando o contato e ingestão com substâncias que Ihes conferem certo perigo (AMORIM, 2017; DOMINGOS, 2016). 
O controle insuficiente de prescrições e comercialização de medicamentos bem como a curiosidade inerente à faixa etária são fatores que contribuem para esse padrão. $O$ armazenamento inadequado de produtos de uso doméstico, agrotóxicos, produtos de uso veterinário, medicamentos e outros produtos contendo substâncias potencialmente tóxicas é um dos fatores de maior relevância na discussão de estratégias para evitar os acidentes envolvendo crianças. Locais de fácil acesso à criança, armários ou gavetas sem chaves não são adequados para manter produtos tóxicos. Segundo estudos, a orientação aos pais e às crianças de forma isolada não tem demonstrado eficiência para evitar acidentes (ALBUQUERQUE, 2017; AMORIM, 2017).

\subsection{DISTRIBUIÇÃO DE CASOS DE INTOXICAÇÃO POR SUBSTÂNCIAS CONFORME A CIRCUNSTÂNCIA DO EVENTO}

Em 2007 foi registrado 1 caso de tentativa de suicídio com uso de substância química por criança menor de 1 ano. Considera-se que esse dado foi registrado equivocadamente, uma vez que menores de 1 ano não são capazes de atentar contra sua própria vida.

Não estão registrados outros tipos de circunstâncias, nem com relação aos acidentes por substâncias químicas nem por animais peçonhentos, sendo que a plataforma DATASUS permite que sejam inseridas as informações: uso habitual, acidental, ambiental, uso terapêutico, prescrição médica, erro de medicação, automedicação, abuso, tentativa de suicídio, tentativa de aborto, violência/homicídio (MINISTÉRIO DA SAÚDE, 2019).

\section{CONCLUSÕES}

- Foram registrados 14 casos de intoxicação exógena causadas por substâncias tóxicas e 1.000 casos de acidentes por acidentes por animais peçonhentos em crianças de 0 a 9 anos, no período de 2007 a 2017, no Estado do Amapá.

- O número de casos de intoxicações mostrou-se consideravelmente crescente ao longo dos 10 anos estudados. 
- Os meninos são mais acometidos que as meninas.

- O principal agente causador de acidentes em geral é a serpente do gênero Bothrops. As substâncias exógenas tiveram igual número de notificação entre medicamentos, raticidas e domissanitários.

- Todos os casos de intoxicação receberam desfecho favorável, com alta após cura.

- Os acidentes aconteceram em sua maioria no mês de Junho e o primeiro semestre foi o período em que houve mais registros.

- Houve apenas um registro da circunstância do evento (tentativa de suicídio), mas que deve ser considerada erro de notificação, por ter acontecido com criança menor de 1 ano.

- A faixa etária mais acometida por animais peçonhentos foi de 5 a 9 anos, já a faixa de 1 a 4 anos foi mais acometida por intoxicações por substâncias tóxicas.

\section{CONSIDERAÇÕES FINAIS}

Não foi possível analisar a diferença entre as espécies e gêneros de escorpiões e lagartas, pois a plataforma DATASUS não oferece essa opção de registro. Não foi possível também destacar quais os medicamentos são mais prevalentes nos casos de intoxicação exógena por substâncias nocivas, pois a plataforma também não oferece essa opção. Considera-se que esses dados são de extrema relevância no contexto da intoxicação, pois permite melhor direcionamento do atendimento às vítimas. Assim, os autores consideram significativo sugerir aos órgãos competentes, a inclusão dessas opções de registro no DATASUS.

Espera-se que, com a implantação do CEATOX no Estado, possa ser possível traçar um perfil mais detalhado sobre esses casos, uma vez que o trabalho desse serviço também inclui a pesquisa epidemiológica.

Os autores deste estudo consideram que, apesar de haver dúvidas quanto subnotificação dos dados, a presente pesquisa é de extrema relevância ao cenário da saúde pública local e que partir desses dados, é possível traçar metas de melhorias ao serviço de atendimento às vítimas de intoxicação. 


\section{REFERÊNCIAS}

ALBURQUERQUE, PLMM. Intoxicações agudas: guia prático para o tratamento. Fortaleza: Soneto Editora, 2017.

AMORIM, MLP; MELO, MJG; SIQUEIRA, MT. Intoxicações em crianças e adolescentes notificadas em um centro de toxicologia no nordeste do Brasil. Rev Bras Saúde Matern Infant Recife, 17(4): 773 - 780 out. / dez., 2017.

BRASIL. Presidência da República. Casa Civil. Subchefia para Assuntos Jurídicos. Lei no 6.259, de 30 de Agosto de 1975.

. Estatuto da Criança e do Adolescente, Lei no 8.069, de 13.07.1990, publicada no DOU de 16.07.1990.

- Fundação Nacional de Saúde. Manual de diagnóstico e tratamento de acidentes por animais peçonhentos. $2^{\mathrm{a}}$ ed. Brasília, 2001.

- Ministério da Saúde (BR), Sistema Nacional de Informações TóxicoFarmacológicas (SINITOX). Casos Registrados de Intoxicação Humana por Agente Tóxico e Faixa Etária. Brasil, 2007.

. Ministério da Saúde. Portaria no 1.130 de 05 de Agosto de 2015. Institui a Política Nacional de Atenção Integral à Saúde da Criança (PNAISC) no âmbito do Sistema Único de Saúde (SUS). Ministério da Saúde, 2015.

. Ministério da Saúde. Portaria oㅡ 204 de 17 de Fevereiro de 2016. Define a Lista Nacional de Notificação Compulsória de doenças, agravos e eventos de saúde pública nos serviços de saúde públicos e privados em todo o território nacional, nos termos do anexo, e dá outras providências. Ministério da Saúde, 2016.

. Ministério da Saúde. Secretaria de Vigilância em Saúde. Departamento de Vigilância em Saúde Ambiental e Saúde do Trabalhador. Instruções para 
preenchimento da Ficha de Investigação de Intoxicação Exógena Sinan - Sistema de Informação de Agravos de Notificação. Brasília, 2018.

. Agência Nacional de Vigilância Sanitária. Disque-Intoxicação. Disponível em: $<$ http://portal.anvisa.gov.br/disqueintoxicacao >. Acesso em 20 de março de 2019.

BRITO, JG; MARTINS, CBG. Intoxicação acidental na população infantojuvenil em ambiente domiciliar: perfil dos atendimentos de emergência. Rev Esc Enferm USP. 2015; 49(3):373-380

BUCARETCHI, F; BARACAT, ECE. Exposições tóxicas agudas em crianças: um panorama. Jornal de Pediatria. Sociedade Brasileira de Pediatria. 2005; 81(5 Supl): S212-S222. Rio de Janeiro, 2005

CANTINHO JÚNIOR, JJ. Acidentes por animais peçonhentos no estado do Piauí entre 2007 até 2014: uma série de casos. [Dissertação de Mestrado]. Teresina: Instituto Oswaldo Cruz, Pós-Graduação em Medicina Tropical; 2016.

CHEUNG, R; MACHADO, C. Acidentes por animais peçonhentos na região dos lagos, Rio de Janeiro, Brasil. Journal Health NPEPS. 2017; 2(Supl.1):73-87.

DOMINGOS, SM; BORGHESAN, NBA; MERINO, MFGL; HIGARASHI, IH. Internações por intoxicação de crianças de zero a 14 anos em hospital de ensino no sul do Brasil, 2006 - 2011. Epidemiol Serv Saúde, Brasília, 25(2): 343 - 350, abr - jun 2016.

FONTANELE, GC; NOBRE, MP; PRADO, RMS; SANTOS, SLF; TORRES, KB. Análise de Intoxicações em Crianças Atendidas no Centro de Assistência Toxicológica do Estado do Ceará. Boletim Informativo Geum, v. 6, n. 1, p. 33 - 42, jan./mar., 2015.

GUMMIN, DD et al. Annual Report of the American Association of Poison Control Centers' National Poison Data System (NPDS): 35th Annual Report, Clinical Toxicology. 2017. DOI: 10.1080/15563650.2018.1533727. 
MARTINS, A; BECIL JUNIOR, MR. Acidentes com animais peçonhentos da ordem hymenoptera (abelhas e vespas): principais complicações em países da América Latina e Caribe. Braz. J. Hea. Rev., Curitiba, v 1, n. 1, p. 220 - 232, jul./set. 2018.

MESCHIAL, WC; MARTINS, BF; REIS, LM; BALLANI, TSL; BARBOZA, CL; OLIVEIRA, MLF. Internações hospitalares de vítimas de acidentes por animais peçonhentos. Rev Rene. 2013; 14(2):311-9.

MINISTÉRIO DA SAÚDE. DEPARTAMENTO DE INFORMÁTICA DO SUS DATASUS. Informações de Saúde. Disponível em: $<$ http://tabnet.datasus.gov.br/cgi/tabcgi.exe?sinannet/cnv/Intoxbr.def>. Acessado em 01 de agosto de 2019.

SBP. Sociedade Brasileira de Pediatria. PERGUNTE AO ESPECIALISTA - DC ADOLESCÊNCIA. Departamento de Adolescência da Sociedade Brasileira de Pediatria, 2017.

SILVA, AM; BERNARDE, PS; ABREU, LC. Accidents with poisonous animals in Brazil by age and sex. Journal of Human Growth and Development, 2015; 25(1): 54-62.

TAVARES, EO; BURIOLA, AA; SANTOS, JAT; BALLANI, TSL; OLIVEIRA, MLF. Fatores associados à intoxicação infantil. Esc Anna Nery (impr.) 2013 jan - mar; 17(1): $31-37$.

VILAÇA, L; CARDOSO, PR. Intoxicações na infância: panorama geral do perfil das intoxicações em diferentes países. Rev Med Minas Gerais 2014; 24 (1): 21 - 25.

WHO - World Health Organization. Rabies and envenomings: a neglected public health issue: report of a Consultative Meeting. World Health Organization, editor. WHO. Geneve; 2007.

World report on child injury prevention. Children and poisoning. World Health Organization, editor. WHO. Geneve; 2008. 


\section{Snakebite}

envenoming.

Disponível

em

$<$ <ttps://www.who.int/snakebites/disease/en/>. Acesso em 14 de março de 2019.

7. www2.datasus.gov.br

Enviado: Agosto, 2019.

Aprovado: Setembro, 2019. 